\title{
Eurípides: de la moral pensada a la moral vivida
}

\author{
Euripides: from thought morality \\ to lived morality
}

\author{
ENRIQUE HERRERAS
}

Universitat de València (España)

Recibido: 23-12-2010

Aprobado definitivamente: $30-06-2011$

\section{RESUMEN}

La tragedia griega sigue siendo un gran referente de reflexión filosófica. En este artículo nos centraremos en la figura de Eurípides, concretamente en el tema de los juicios morales que trasmiten sus obras trágicas. La cuestión es que si en Esquilo la razón triunfaba sobre el dilema trágico, en Eurípides no se ve claro ese triunfo si viene impuesto desde fuera y no ha arraigado en el corazón de los ciudadanos. La razón tiene muchas dificultades para ejercer su control sobre la acción y orientarla hacia el bien común. Eurípides planteará que es la persona, su conciencia interior, la que debe de estar convencida de que algo le obligue moralmente. El paso de una moral pensada a una moral vivida.

\section{PALABRAS CLAVE \\ RAZÓN, PASIÓN, CONCIENCIA INTERIOR, OBLIGACIÓN MORAL, MORAL PENSADA, MORAL VIVIDA}

\begin{abstract}
The Greek tragedy is still an important reference for philosophical reflection. In this article we will focus on the figure of Euripides, specifically on the issue of moral judgments his tragic plays transmit. The issue is that if in Aeschylus reason prevailed over the tragic dilemma, in
\end{abstract}


Euripides it is not clear if that triumph is imposed from outside and has not rooted in the heart of the citizens. Reason faces much difficulty to exercise its control over action and go for the common good. Euripides proposes that it is the person, their inner consciousness, which must be convinced that something should oblige them morally. It's the passage from a thought morality to a lived morality.

\section{KEYWORDS}

REASON, PASSION, INNER CONSCIOUSNESS, MORAL OBLIGATION, THOUGHT MORALITY, LIVED MORALITY

\section{UNA ÉPOCA EN CRISIS}

LA VIDA DE EURÍPIDES (484-406 a.C.) transcurre en plena Guerra del Peloponeso, y, por tanto, en la decadencia de la democracia ateniense. Es la suya, una época en donde la incertidumbre y la inseguridad se extienden por todas partes, y en este panorama, el autor crea unos personajes que son manejados por los hilos de sus pasiones, por ello pretenden convencer a los espectadores, y no decir la verdad, al igual que en los juicios públicos. Lo cual es síntoma, según Jaeger (2004), del aburguesamiento del mito tradicional, y del subjetivismo imperante entonces. De ahí que el mismo Jaeger haya señalado entre sus características está ya lo que hoy llamaríamos «realismo burgués», en el que predomina el gusto por la retórica y la preocupación filosófica. A Eurípides le gustaba reflejar las numerosas antinomias políticas religiosas, morales y educativas mediante discursos antilógicos, tal como hiciera Protágoras.

Sus diecisiete tragedias conservadas representan un cambio de concepción del género trágico, de acuerdo con las nuevas ideas que había aprendido de los sofistas; así, su escepticismo frente a las creencias míticas y religiosas es manifiesto en sus obras, las cuales rebajan el tono heroico y espiritual que habían cultivado Esquilo y Sófocles a un tratamiento más cercano al hombre y la realidad corrientes. En tal sentido se ha señalado que Eurípides es el representante de una época en crisis. No obstante, el trágico sigue manteniendo alguna creencia en una convivencia que se ajuste a la pólis democrática.

\section{I.1. La GUERRa DEL PELOPONESO Y LA SEGUNDA ILUSTRACIÓN SOFÍSTICA}

Si la obra de Eurípides tiene como referente la decadencia vivida en Atenas a partir de la Guerra del Peloponeso, también se infiltra del pensamiento de ese momento dominado por una segunda generación de sofistas que cambian claramente la mentalidad de la primera y que llamaremos Segunda ilustración.

Si la Primera ilustración sofística vibra a raíz de un tono reflexivo positivista, sin embargo, con la etapa que tiene como fondo dicha contienda, el 
planteamiento cambiará claramente de perspectiva y de presupuestos. El primer dato que llega de ese momento está relacionado con el naufragio del intento de concordia (al menos en cuanto a propósito teórico) entre clases divergentes, y la democracia se precipita, por muchas circunstancias añadidas, a un proceso de desintegración.

Es en este paisaje donde se produce una mudanza de ideas que llegan a plantear la liberación del individuo de las servidumbres de la ciudad. Los pensadores de este crucial momento luchan por construir un nuevo orden y sufren y vacilan ante las contradicciones eternas de lo humano. Otros se ponen al servicio de distintos particularismos que hacen olvidar las ideas anteriores centradas en el bien de la comunidad.

En líneas generales, el pensamiento sofístico de este momento propone un humanismo igualitario y hedonista. Por ejemplo, Hipias y Demócrito ya no hablan del ciudadano sino del hombre en general, dando por sentado que la finalidad del gobierno consiste en que el individuo pueda dedicarse a los trabajos de la vida. El individualismo aparece claramente remarcado. Se rompe, por tanto, con la idea de solidaridad del ser humano con la comunidad y su conveniencia. Y, a raíz de todo ello, se abandona, de alguna manera, el deseo de fundamentar el nuevo orden, para buscar «la fortaleza contra la ley y la costumbre (Antifonte).

Los nuevos sofistas dejan de creer en la instituciones al considerar a éstas como obstáculos para el fin primordial del hombre que no es otro que el de buscar la satisfacción de sus apetencias. Vemos, por consiguiente, que en este momento se bosqueja ya el epicureísmo, el alejamiento de la esfera pública y de la política para la búsqueda y preocupación de una vida exclusivamente privada.

También, buena parte de la nueva teoría política tiende a prescindir su preocupación por los problemas propios de los habitantes de una ciudad concreta, para dirigirse a todo el género humano.

La fijación de este nuevo humanismo tendrá, como señala Rodríguez Adrados (1998), consecuencias en la visión política que podríamos resumir de la siguiente manera: Si hace unos años, el pensamiento político democrático se ponía al servicio de la estabilidad de la comunidad, ahora conviven todo tipo de posiciones. Es decir, si en la primera sofística, los valores de lo justo, lo conveniente y lo agradable, así como los del individuo y la comunidad, tendían a coincidir, en esta nueva etapa se pasa a tal ambigüedad que el mismo y básico en otros tiempos concepto de justicia acaba significando muchas cosas distintas: conveniencia del individuo, un simple acuerdo, devolución del trato recibido, una ley moral superior, etc. En este orden de cosas, la señalada conveniencia del individuo, o por buscar otros campos, la del partido o la del gobierno, trae como consecuencia la rebaja de la validez de las normas fijas. 
Se abre paso, como subraya Rodríguez Adrados, a una visión más «real» de la política, incluso a posiciones irracionales, como la recuperación de la teoría de la ley del más fuerte.

Recordemos que la política, para la Primera ilustración, era una técnica o arte basado en el conocimiento de la naturaleza humana, ahora dicha naturaleza se la considera más compleja.

En suma, en esta época se produce una inversión de valores, que va unido a una desmoralización en el campo de la política al provocar un relativismo a ultranza.

Es importante también, para comprender el contexto en el que se desenvuelve Eurípides, la descripción que hace Tucídides en La Guerra del Peloponeso, obra donde se percibe la vida política en tiempos de guerra y de la que recojo algunos fragmentos del Libro III, cuando el historiador habla de Corcira y su guerra civil, y en concreto del capítulo titulado «Consecuencias morales de la guerra civil», que se encuentran entre los párrafos 82 y 84 :

Los vínculos de sangre llegaron a ser más débiles que los vínculos de partido [...] La causa de todos estos males era el deseo de poder inspirado por la codicia y la ambición; y de estas dos pasiones, cuando estallaban las rivalidades de partido, surgía el fanatismo. Los jefes de partido ostentaban en sus banderas, unos, la igualdad de derechos, otros, una aristocracia moderada, pero bajo esa máscara, en realidad, sólo trataban de suplantarse mutuamente, pues lo mismo da que gobiernen unos o que gobiernen otros. Daban rienda suelta a sus deseos y rencores, y sin más ley que el propio ardid menospreciaban la justicia y el bien común. Llegados al poder satisfacían sus odios personales a fuerza de sentencias inicuas y descaradas violencias, ninguno respetaba la buena fe. [...] De esta forma, ni unos ni otros se regían por moralidad alguna, sino que aquellos que, gracias a la seducción de sus palabras, conseguían llevar a término alguna empresa odiosa, veían acrecentado su renombre. [...] El dios Éxito era el único en cuyos altares se sacrificaba y el perpetrador de algún negro delito como supiera encubrirlo, con apariencia de honradez, podía estar seguro de la pública estimación. [...] Los ciudadanos que estaban en una posición intermedia eran víctimas de los partidos, bien porque no colaboraban en la lucha, bien por envidia de su supervivencia.

Y he aquí algunas consecuencias que ve Tucídides, letales para la sociedad democrática: «Así fue como la perversidad en todas sus formas se instaló en el mundo griego a raíz de las luchas civiles [...] Y los espíritus más mediocres triunfaban las más de las veces».

De este texto, sin duda inquietante, emana de inmediato algunos asuntos que tienen que ver con el imaginario democrático. Tucídides nos alumbra hacia un «descrédito de la política», una desconfianza respecto a sus protagonistas y, en definitiva, expresa una torpeza secular de las sociedades cuando han tenido 
en sus manos la soberanía. La referencia al dios del Éxito es otro paralelismo inquietante, con el consiguiente desprecio del bien común.

\section{LA HUMANIZACIÓN DE LOS HÉROES Y LOS DIOSES}

Una vez vislumbrado el contexto, una buena manera de empezar a comprender, con cierta rapidez, a Eurípides, puede consistir en la lectura de su obra Electra, y relacionar al personaje que da nombre al texto con los otros creados por Sófocles y Esquilo que mantienen el mismo título.

Esquilo, por ejemplo, plantea a su Electra con una intención claramente moral, un personaje portador de un equilibrio, el que sirve para contrarrestar el asesinato de su madre (Clitemnestra) a su padre (Agamenón). Un crimen que Esquilo esboza, en cierta manera, como paso previo para que finalmente irradie la justicia.

En Sófocles, desde luego, el centro de la obra lo constituye Electra; pero el interés no se centra en el matricidio, porque el clímax no se organiza ya sobre la muerte de Clitemnestra, sino sobre la de su amante, Egisto. Tampoco se esboza un problema puramente moral, ya que el matricidio no aflora como una etapa previa a la consecución de la auténtica justicia, como ocurría en Esquilo. Desde esta perspectiva podríamos observar que lo principal de la versión sofóclea es el estudio del carácter de Electra. A raíz de esta consideración, nos atrevemos a aseverar, siguiendo a Kitto, que si bien Sófocles nos llama la atención sobre la dinámica de la díke, lo hace sin entender díke como justicia moralizadora, al modo de Esquilo, sino como equilibrio, como una especie de mano invisible que se inserta en el orden normal de las cosas. Un concepto, pues, que presupone una identificación del mundo físico y humano, ya que los protagonistas (Electra y Orestes) actúan con la frialdad de los ejecutores de un crimen necesario (cf. Kitto 1966, p. 131).

Eurípides, por su parte, mantiene el protagonismo de Electra al igual que Sófocles, pero ahora vuelve a simbolizar un problema moral. Esta interpretación choca con aquella que destaca, ante todo, la pericia teatral de Eurípides. Por ejemplo, y ya que estamos con Kitto, para este autor, la Electra de Eurípides es sólo un buen melodrama. Resulta inútil buscar una idea trágica en esta obra, dado que, según él, lo que pretende Eurípides es mantener el interés del espectador con efectos dramáticos, los que siempre surgen del tema de la venganza. A decir verdad, Kitto se refiere a que sobre dicha venganza poco puede decirse desde el punto de vista moral. De ahí que esté inserto en una opinión bastante extendida, la de considerar a Eurípides, «un gran autor teatral que conoce claramente los trucos para despertar el interés del espectador» (Kitto 1966. p. 330).

Por nuestra parte, y sin dejar de lado esta visión -es cierto, Eurípides es un gran artesano, sobre todo en la riqueza de caracteres que imprimen sus obras-, 
opinamos que sí hay en su obra una nueva manera de exponer el tema de la venganza. En concreto, su aportación estriba en suprimir la importancia del elemento divino, tan fundamental en sus predecesores, y, sobre todo, en humanizar el drama, esto es, hacer a los personajes más cercanos a los espectadores, dar mayor verosimilitud a las acciones que acontecen.

Estos dos elementos son fundamentales para entender a Eurípides. Y también para vislumbrar la obra que estamos tratando, Electra, una historia, una fábula, convertida en manos de este trágico en un drama familiar.

Para ello, Eurípides -otra característica importante del autor-se ve impelido a forzar el mito y llevarlo, conducirlo, a su terreno, a un innovador ambiente psicológico. Del mito, Eurípides suprime los elementos más notablemente religiosos: los mismos personajes dudan de que Apolo haya dado la orden; ya no hay rito funerario en la tumba de Agamenón; no hay sueño de Clitemnestra. En cambio, se plantean situaciones más realistas. Por ejemplo, a Electra se le fuerza a casar con un campesino para que sus posibles hijos no nazcan de estirpe noble y, por tanto, sean vengadores en potencia; Orestes no entra en Argos para matar allí a Clitemnestra y a Egisto, sino que el autor los hace salir del palacio para que su asesinato sea más verosímil

Tampoco el Orestes de Eurípides es el mismo que el de las obras firmadas por Esquilo y Sófocles. Ahora, este personaje vive la venganza sumido en contradicciones. Es consciente de que no ha sido Apolo el impulsor de su acto matricida. No es el ejecutor firme de la orden de dicho dios como se nos mostraba en los personajes de los otros trágicos, sino un adolescente confuso y fluctuante.

Eurípides resalta el lado humano de las motivaciones de los dos hermanos. En su actuación, además de la venganza por el asesinato del padre (Agamenón), se juntan otros motivos tan palmarios como el hecho de que Orestes haya sido desposeído de su Reino, o que Electra, como dijimos, se sienta vejada al ser entregada en matrimonio a un campesino. Por cierto, éste personaje mantiene posturas, en contra de lo que se pueda suponer, muy clarividentes, lo que nos abre a otro tema fundamental de Eurípides: la consideración de cierta igualdad de las clases sociales. Al menos, en inteligencia. Es normal que en sus obras aparezcan algunos criados, portadores de mucho mayor raciocinio y sensatez que sus amos.

Así, pues, comparada su obra con la de los otros autores trágicos, Eurípides se interesa más por los individuos que por la comunidad, más por las pasiones (odio, venganza, amor) que por cuestiones de religión o moral. Eurípides profundiza en la preocupación anímica de los personajes, por ello se le ha llamado el «primer psicólogo». 
En la obra de Eurípides hay tragedia, hay sufrimiento de unos seres, muy humanos, que se debaten entre el odio, el crimen y los remordimientos. Brinda siempre a sus personajes que expongan sus razones, incluso cuando sufren un estado febril. Es el caso de Medea. Aún así, viven dichas razones con contradicciones, como cuando Clitemnestra, después de todo lo hecho a Electra, cae en sus redes al ir rauda a ayudar a su hija tras haberle anunciado el embarazo de la misma (la trampa para tenerla cerca y así poder matarla): «Te perdono, porque en verdad no me alegro en exceso de mis acciones» (v. 1105). Pero hay algo superior a dichas negaciones, como aclara seguidamente la propia Clitemnestra: «Tengo miedo y miro por mis intereses» (v. 1115).

Esta pequeña muestra nos da una idea de cómo actúan los personajes creados por Eurípides, dentro de un mundo, de una atmósfera que queda bien patente en la siguiente frase pronunciada por Orestes: «Y es que la naturaleza humana está en confusión» (v. 365).

Entramos, pues, con Eurípides, en una crisis de los fundamentos míticos y en la pérdida del talante heroico de los personajes trágicos, vueltos «demasiado humanos», como ocurre en casi todos sus dramas. De ahí que, frente a esa fe en el progreso que veíamos en Esquilo, en Eurípides se haya diluido en pesimismo (ahora sí lo parece) y desaliento. La acusación de Nietzsche (2005) contra Eurípides, al describirlo como decadente, tiene mayor sentido cuando vemos su amarga representación de un mundo donde la intervención divina, como ya hemos señalado, resulta caprichosa y donde el triunfo está desligado de toda moralidad y aboca a una visión negativa de la existencia humana.

Para Eurípides, el mundo carece de orden, y si existe algún orden, éste no se encuentra al alcance del ser humano. Por tanto, en la confusión descrita anteriormente tienen mucho que ver los dioses ya que el mundo de lo divino retrocede ante el mundo de lo puramente humano regido por la diosa Fortuna.

Una fortuna que nunca deja que algo tenga su final, y ello a pesar de que muchas obras de Eurípides acaban con el conocido Deus ex machina, esto es, una especie de Happy End, lo que nunca vimos en Sófocles, aunque, en cierta manera, sí en Esquilo si recordamos el aire conciliador del que se nutren sus finales. No obstante, dichos finales de Eurípides puede que ocurran por la búsqueda de una conclusión que calme el sufrimiento, dado que el infortunio nunca acaba, o no tiene trazas de acabar.

El héroe de Esquilo abriga una confianza firme para poder pasar por encima del destino, de un destino que conoce bien. Los personajes de Sófocles no saben realmente lo que están haciendo y, cuando toman consciencia de ello, ya es tarde, pero esa ignorancia, ese mal conocimiento procede en realidad de una deficiente armonización del ser humano con el devenir de las cosas y, finalmente, tras su vivencia, como ya vimos, el héroe se abre a un mayor saber 
de la vida. En cambio, los personajes de Eurípides ven el mundo golpeado por fuerzas, en las que algunos han querido ver divinidades, pero que en el fondo no son más que pasiones humanas, pasiones destructoras que se apoderan del ser humano y lo arrastran a la destrucción. Consciente de ello, al ser humano, lo único que le queda es la inseguridad, el desasosiego, cuando no el miedo (cf. Di Benedetto 1971, p. 151).

En la obra de Eurípides se resquebraja la imagen de los dioses. Dice Clitemnestra en Ifigenia en Áulide: «si existen dioses, tú, desde luego, por ser un hombre justo, obtendrás dicha recompensa. Y si no, ¿de qué vale esforzarse?» (vv. 1030-1035). Y en esto llegamos al límite del contenido de Eurípides que, según K. Reinhardt (1972), tiene que ver con un sentimiento de absurdo, de la falta de sentido en la acción humana, reflejado en la triste experiencia de una generación que, como vimos en anteriores capítulos, ha sufrido los desastres de una larga guerra y la crisis de valores tradicionales, que perdió la fe en los dioses y, con ello, el sentido de la existencia.

También los héroes de estos patéticos melodramas son sólo trasuntos de lo que fueron. Conservan sus nombres famosos, pero han perdido ya su valor para la acción noble, desconfiados en su destino y en su propia naturaleza. En Orestes, como hemos señalado, encontramos al matricida vengador de Agamenón postrado y enloquecido. Las furiosas Erinis, las diosas de la venganza tribal que ya aparecieron en la tercera obra de La Orestiada de Esquilo, se han convertido en producto de la imaginación delirante de Orestes. Por ello, se escapan de la lucidez que viven en aquella obra cuando aceptan el veredicto del Areópago. Porque, como dice M. Delcourt «han dejado de serle exteriores al personaje, viven en su interior» (Delcourt 1962, p. 114).

Ahora, los remordimientos acompañan a la ansía y necesidad de venganza. La procesión va por dentro. Porque vemos, más bien, las reacciones psicológicas de unos personajes asediados por dichas aflicciones. Orestes ya no está sujeto a ningún destino trágico, sino que yerra dispuesto a cualquier nuevo crimen con tal de sobrevivir en un mundo sin valores. Es ya un personaje sin grandeza moral, por ello, según sus propias palabras, «somos esclavos de los dioses, sean lo que sean los dioses» (v. 415). Cuando el dios Apolo, al final de Orestes acude a remediar el caos y evitar la catástrofe, no queda por ello mejor parado. La ambigüedad de sus oráculos, la tardanza en su auxilio y lo precario de la solución quedan en evidencia. Dice el Mensajero en la obra Helena: $«_{i} \mathrm{Oh}$ hija, qué inconstante y difícil de entender es la divinidad! ¡Con qué facilidad lo cambia todo y lo trae y lo lleva de un lado a otro! Un hombre sufre; otro, que ha empezado por no sufrir, muere más tarde miserablemente, sin haber podido gozar de una buena fortuna estable» (v. 715).

El coro añade después: 
¿Qué mortal podrá distinguir, después de interminables búsquedas, qué es dios y qué no es dios, o qué está en medio de ambos términos, cuando ve que los dioses obran primero sin sentido, y luego en el contrario, sin que en ningún momento encarnen otra cosa que capricho, siempre imprevistos y contradictorios? (v. 1140).

\section{DE LA CRISIS A UN NUEVO MORALISMO}

Tanto héroes como dioses forman parte de una crisis religiosa y social. Eurípides acaba aportando un moralismo basado en la conciencia del hombre. Moralismo de base, si se quiere, ya que en sus personajes la razón establece unas normas de conducta fundadas en la conciencia del mismo. Por ello, este trágico busca los horizontes de la virtud y del vicio, pero mostrando los comportamientos humanos y no llegando a conclusiones determinantes, como hiciera Sócrates. Sin llegar al moralismo socrático, que distingue la virtud del vicio, Eurípides expone, critica, pero ante todo intenta comprender (llegando incluso a compadecerse por sus personajes), más que juzgar.

Eurípides no se contenta con la doctrina de la ignorancia de Sócrates, le preocupa, y mucho, el desorden, por lo que no deja de distinguir y de indagar sobre la acción moral e inmoral. Pero su gran descubrimiento, su dramático descubrimiento, es que muchas veces la segunda está escondida detrás de una justificación divina.

En todo caso, lo que le interesa es decir bien alto que la moralidad está estrechamente ligada al individuo. «Un saber consigo mismo», en palabras de Rodríguez Adrados, «un saber que separa lo que debemos hacer de sus consecuencias y de posibles juicios extraños a nosotros» (Rodríguez Adrados 1998, p. 306). Cuando Menelao, viendo la locura de Orestes, le pregunta qué enfermedad padece, éste le contesta: mi entendimiento, porque sé que he hecho algo terrible (dar muerte a su madre). Pese a la orden de Apolo, la conciencia se rebela y le indica que ha obrado mal

A Eurípides le inquieta que el pensamiento no domine la acción de los personajes. Ahí está el remordimiento que sufren Medea y Fedra. En Hipólito, Fedra confiesa a su nodriza (que es el contrapunto de la pasión, es decir, la sensatez) que sus manos están puras, pero su alma es la que tiene la mancha (el amor por su hijastro Hipólito). Este personaje, como todos los héroes de Eurípides cae en el remordimiento, interioriza una norma de conducta y choca con el problema de la responsabilidad. En Medea domina la pasión sobre la razón (¿un hecho real o una excusa para justificar sus planes?). Otras veces hay un falso pretexto que encubre al hombre culpable: la fuerza irresistible representada como acción de la divinidad. Es lo que ocurre en Las Troyanas, donde Helena llega a defenderse, es decir, a esconder su responsabilidad, atribuyendo 
a Afrodita la culpa de su huida con Paris. Pero Hécuba le responde que fue su espíritu el que se convirtió en Afrodita.

En consecuencia, hay en Eurípides un antes y un después con respecto a Sófocles y Esquilo, ya que la acción de sus personajes ya no posee un doble componente divino y humano, ahora es sólo humano. Terriblemente humano. Edipo repite una y otra vez su involuntariedad, Medea reconoce que es ella la que toma la decisión, aunque ésta llegue después de una guerra interna.

\section{Un TEATRO EXISTENCIALISTA}

Eurípides refleja una nueva concepción del individuo en plena crisis de la democracia, de sus creencias y valores. Frente al optimismo y a una fe extraordinaria en el progreso, que caracteriza a la Atenas que sale victoriosa frente a los persas, la de Esquilo, y en parte también la de Sófocles, el pesimismo y el desaliento caracterizan al mundo de Eurípides. En su tiempo el mundo pensado por los intelectuales del momento carece ya de orden -y si lo hay no está al alcance de los hombres-, además de radicalizarse la percepción de que la actuación de la divinidad es arbitraria e imposible de comprender.

Por ello hay en su obra una crítica a los viejos mitos y a las creencias tradicionales. Esta posición es vista por García Gual (1990) como una veta ilustrada, la de un racionalista que analiza esa realidad desde una perspectiva lógica. Por ello, al ver de cara la realidad, nos propone unos personajes menos seguros de sí mismos, más complejos y, a la vez, más próximos al hombre corriente. Su descripción psicológica desmonta a los héroes trágicos y todo se discute en sus dramas, repletos de enfrentamientos dialécticos. Entre personajes, y en el interior de los propios personajes consigo mismo.

Notablemente, Eurípides ${ }^{1}$ se opone a las tesis optimistas de Sócrates, las que versan sobre la consideración de la razón como más fuerte que los sentimientos y que los actos inmorales se comenten por ignorancia. Medea afirma que conoce los males que va a cometer, pero que su pasión es superior a sus razonamientos. Por otro lado, la lucidez en los razonamientos, o la sensatez tampoco mitiga los sufrimientos, y muchas veces más que ayudar a resolver la cuestión, la empeora, como ocurre en el caso de la Nodriza de Fedra, en Hipólito.

De ahí que cuando se habla de Eurípides como racionalista, habría que tener en cuenta esto último, que el buen razonamiento tampoco da un pasaporte para solucionar conflictos.

Pero, ¿esta observación nos conduce necesariamente al otro extremo, al de Dodds, quien utiliza a Eurípides muy claramente para argumentar su visión

1 En esto diferimos de la visión de Nietzsche quien suele considerar a Eurípides como el trasmisor de las ideas de Sócrates en la tragedia, y, por tanto, su destructor. 
del irracionalismo de los griegos, y su interés por encontrar los aspectos más oscuros del alma humana?

No nos introduciremos en este debate, ya que pensamos que debiéramos ir más allá de estos calificativos (racionalista o irracionalista), porque el fin de Eurípides es presentar a los seres humanos como son. Por ello desmonta el entramado heroico y presenta figuras descentradas.

Eurípides puede considerarse, desde nuestro punto de vista, un existencialista, porque no pretende sustituir al hombre de carne por un hombre reflejo. Más que un mundo armonioso e imaginario presenta un mundo repleto de conflictos, en que salen gritando las pasiones por debajo de las razones.

Como años después percibirá Albert Camus (1996), en Eurípides ya divisamos al pensador que mira un mundo de creencias destrozadas. Su compromiso, por tanto, está alejado de la política concreta. Eurípides es un disidente. Un disidente cuya obra no tiene nunca una respuesta fácil ni terminante. Indaga la condición humana y da cuenta de la esperanza de un nuevo sentimiento de salvación, pero sin dejar aclarada la cuestión. Más bien, sus tragedias, incitan a las preguntas más que a las respuestas. Hay en ellas una especie de comprensión hacia sus personajes, incluso hacia la crueldad de Medea. Porque, el ser humano, vendría a decir Eurípides, no se explica sólo mediante sus comportamientos, sino mediante sus relaciones consigo mismo y con el mundo.

Y la realidad le dice a Eurípides que los hombres suelen actuar por intereses. En este contexto, es muy sensible a la pérdida de significado que ha acontecido en su época de palabras fundamentales, como es el caso de la sophrosýne, ahora utilizadas según los intereses de un demagogo, o de un partido. Si Sophrosýne significaba antes autodominio, ahora «éxito». Lo que en otros tiempos eran altos valores, ahora pasan a significar ideas y acciones vergonzosas. Así, en el mundo político que le rodea, la intriga sagaz es considerada como inteligencia política. Perviven las grandes palabras en los políticos, pero ya no luchan por altos ideales, sino por la riqueza y vanidad personal.

$\mathrm{Y}$ es que Eurípides se encuentra con la dificultad de definir lo justo o hermoso, y sólo quiere exponer una serie de hechos, dejando un buen material para que, después, filósofos como Sócrates o Platón lo ordenen y extraigan consecuencias morales

De momento, Eurípides se alarma de la inexistencia de valores absolutos, y de su incapacidad para poder distinguir entre acciones morales e inmorales.

Esta corrupción de la sociedad es vista por Eurípides como una descomposición del hombre. Por ello hay algo clínico en la obra de Eurípides, sobre todo en su reivindicación del interior humano hasta ahora usurpado por los dioses.

Sin embargo, ello no quita para que haya en él algo «más que humano», algo trascendente que reside en lo humano mismo. Lo humano mismo que, por 
primera vez, se hace consciente. Los cirujanos tienen en común con los profetas que piensan y operan en función del porvenir. Parece que Eurípides no pensó nunca sino en función de un apocalipsis futuro, no para ensalzarlo, pues adivinaba el aspecto sórdido que ese apocalipsis tomaría al final, sino para evitarlo y transformarlo en renacimiento.

Lo fundamental es que - parece pensar Eurípides- el fenómeno de la degradación de valores se repetirá mientras la naturaleza humana sea la misma. Y esto lo hace en un momento en que se empieza a distinguir lo bueno «según la ley» y lo bueno por naturaleza.

El teatro de Eurípides tiene algo que ver con Heráclito, al percibir que el mundo es oposición y guerra; pero también desencadenamiento de los contrastes morales y de los afectos. En ese contexto puede que perviva en su obra una desconfianza en la razón, en la sabiduría, pero en una razón que claramente no lo es, una razón convertida en mera retórica, ese arte de la palabra que sabe confundir lo que es moral de lo que no es moral. En cierta medida, Eurípides plantea esta situación de forma artística, y da pie a que Sócrates la reconduzca desde una mirada crítica y aún no filosófica.

La retórica es el elemento esencial del lenguaje que utilizan los personajes de Eurípides. Lo invade todo. Incluso en las ocasiones más inesperadas, gustan de discusiones retóricas de las que tan amantes eran los atenienses. En los argones retóricos, los héroes tratan de exculparse a sí mismos, acusando a los dioses, al destino y al azar. Pretenden convencer a los espectadores, no decir la verdad, actúan igual que en los juicios públicos, donde lo importante era persuadir a los jueces (al auditorio en este caso) y no exponer los hechos realmente acaecidos.

Los personajes de Eurípides, resumiríamos, sufren de subjetivismo. Pasa lo mismo con los dioses. Eurípides no borra el sentimiento religioso, no parece que sea agnóstico, pero sí pone en solfa a los dioses del Olimpo, ya que, para él, si los dioses hacen algo vergonzoso es que no son dioses. Si Zeus carece de sabiduría, justicia y bondad, es incluso peor que los hombres. Claramente, Eurípides se posiciona contra la religión que ha llegado a ser oficial, así lo expresa en su obra Ion.

\section{RELACIÓN CON LA DEMOCRACIA}

No faltan en la obra de Eurípides las alusiones a Atenas, que siempre aparece con cierta admiración. Por ejemplo, señala Cástor en un momento de Electra, cuando se refiere a la posible salida de Orestes después de haber asesinado a su madre y a Egisto, que es en Atenas donde el voto es sagrado y firme, y es, por tanto, allí donde debe ser juzgado por el crimen, porque sólo en esa ciudad puede tener garantías de que se impartirá justicia. Otro ejemplo: en Las Suplicantes, 
Eurípides proyecta una nueva luz sobre Atenas, en la figura de Teseo, un héroe modelo, la encarnación del mejor gobernante.

Pero esa ciudad ideal es constantemente traicionada por algunas decisiones, por los demagogos, y por decisiones como la que promueven guerras de conquista. De ahí que V. E. Juliá subraye lo siguiente:

[L]a mirada de Eurípides sobre la realidad política que le circunda es fuertemente crítica como sólo puede serlo la de quien está profundamente comprometido con ella, y da lugar a una producción de apariencia contradictoria: por un lado, participa de lo nuevo, del espíritu de la época, del orgullo de ser ciudadano de Atenas: por otro, repudia las desviaciones y abusos del imperialismo ateniense. (Juliá 2006, p. 100).

Igual que el hombre, la democracia también tendría sus contradicciones interiores, ya que en ella persisten muchos desajustes provenientes de la etapa predemocrática, corrientes subterráneas que nunca dejan de estar presentes. Por otro lado, si la democracia, parece decir Eurípides, ya no se atiene a unos valores, pierde su sentido. De ahí que ponga en tela de juicio, con sus medios expresivos, las instituciones de su tiempo.

Las obras de Eurípides son una sala de debates, en los cuales se desarrolla un carácter problemático de las cosas, sobre todo los que tiene que ver con las relaciones humanas. Las acciones de los personajes ya no tienen una justificación religiosa. Tampoco el insaciable afán de felicidad y de justicia puede satisfacerse en este mundo. Un discernimiento nos lleva a otros, ya que si el hombre llega a lo más alto en su aspiración de libertad, se ve obligado a reconocer su carencia absoluta de libertad. O, como indica Hécuba: «ningún mortal es libre: o es esclavo del dinero o de su destino; o la masa que gobierna el estado o las limitaciones de la ley, le impiden vivir de acuerdo con su albedrío» (v. 864).

Por tanto, podemos señalar, con Jaeger, que Eurípides ni es racional ni irracional, como tantas veces se discute, sino que crítica lo irracional en lo racional del alma, algo que observamos en Las Bacantes.

Eurípides no propone un tipo de arte que se funda en la ciudadanía, sino en la vida misma. Por ello niega lo convencional y revela lo problemático. Para comprender mejor esto habría que acudir a Dilthey, para quien las ideas del mundo son formas de responder al misterio de la vida, por eso no son meros «productos del pensamiento», «no surgen de la mera voluntad de conocer», «brotan de la conducta vital, de la experiencia de la vida» (Dilthey 1974, p. 49).

Por ahí anda la humanidad que Eurípides descubre desde un sentido de lo absurdo, de la opacidad humana. Su obra recibe las vibraciones que le llegan de su momento político y cultural, al liberar al individuo de las servidumbres de la ciudad y a la ciudad de las servidumbres de las normas generales de la 
sociedad humana y de los dioses. Eurípides percibe el nuevo orden pero vacila ante las contradicciones eternas de lo humano, al ver que su ciudad se suicida en una guerra. Asimismo alienta una defensa de todo el género humano y no sólo de sus conciudadanos. La sociedad humana más que la sociedad ateniense. De ahí, la importancia que adquieren el esclavo y la mujer en sus obras.

\section{PAIDEÍA EURÍPIDEA}

La tragedia, en las manos de Eurípides, es un espejo, como dice Rodríguez Adrados, de las discusiones intelectuales de su época (1998, p. 340). De alguna manera, siente admiración por la sabiduría, pero no por el arte de la palabra que suele encubrir a verdaderos malvados. Sus obras son, a fin de cuentas, escenarios donde la grandeza y miseria de las palabras entran en batalla, donde la sabiduría adquiere un doble sentido. Tan sabio puede ser el no demagogo que el demagogo, pero este último se suele llevar el gato al agua.

De ahí que Eurípides proponga la interiorización de las normas de conducta. Aún así, el problema surge cuando un personaje no puede hacer lo que quiere (he ahí su tragedia). Pero ésa es la realidad que Eurípides plantea frente a todo intento de conveniencia, de proyección de un mundo ficticio e idealizado, convencional y estético (cf. Jaeger 2004, p. 312).

La creciente libertad individual, política y espiritual que vive su época tiene su otro rostro para Eurípides, ya que esta situación hace más perceptible el carácter problemático de la sociedad humana. Como explica Jaeger, el antiguo concepto de culpa era objetivo, ya que podía caer sobre el hombre una maldición o una mancha sin que interviniera para nada su conocimiento ni su voluntad. Tanto las obras de Esquilo como las de Sófocles, estaban impregnadas de esta antigua idea religiosa. A fin de cuentas, los protagonistas de Sófocles y de Esquilo son «culpables» en el sentido de maldición que pesa sobre ellos, pero inocentes desde el punto de vista del espectador que ve, como queda claro en Edipo, su involuntariedad. En cambio, en Eurípides ya nadie es inocente, de esa forma se subjetiviza el problema de la responsabilidad (cf. Jaeger 2004, p. 315).

Los personajes en Eurípides poseen un sentimiento moral que vive en ellos. Impulsos, sentimientos y voliciones constituyen la base motivacional de los mismos. Parece, pues, como señala Jaeger, que superan la dicotomía del ser y el deber ser (cf. Jaeger 2004, p. 322). De todos modos, esto no está tan claro, según nuestra opinión, porque sí perciben un deber, por mucho que se dejen llevar por su ser. Es el caso de Medea, pero también el de Orestes.

Dice Menelao en la obra Orestes: «¿Qué opresión sufres? ¿Qué enfermedad te destruye?» Y Orestes contesta: «La conciencia, porque sé que he cometido actos terribles» (v. 395). 
Lo evidente, a nuestro entender, es que la voluntad en los personajes de Eurípides es el núcleo de la conciencia, porque, como ocurre con Medea, sólo se experimenta como realidad en y por la voluntad misma, porque sólo la voluntad choca con obstáculos y sólo como consecuencia de esta experiencia surge la contraposición de sí mismo y del mundo. Hay en estos personajes una voluntad de vida, o incluso, vaya, una posible voluntad de poder como diría Nietzsche.

El conocimiento, ciertamente, para Eurípides, no puede retrotraerse por detrás de la vida, siempre hay acontecimientos que nos rebasan. Muchas veces, los personajes de Eurípides no siempre pueden pensar lo que quieren pensar. Por eso nos declara que la libertad está en el conflicto. Sus personajes viven y sufren sentimientos contradictorios, muchas veces con inteligencia calculadora, con afán pragmático de explicar, pero también con sentimientos desenfrenados. Ya lo dice Heracles: «Siendo mortales debemos tener pensamientos mortales» (v. 800). Por ahí anda la posible evolución auspiciada por Eurípides, su paideía, ya que sin ser un verdadero creador de una concepción moral como después lo serán Platón y Aristóteles, sí que exige en su planteamiento la necesidad de aclararse acerca de los juicios morales (ya dijimos que Eurípides ofrece un magnífico material a los filósofos) con los que juzgar determinados comportamientos, no conformándose, como ocurría con Esquilo y con Sófocles, con justificar ciertos actos auxiliado por designios del más allá, o simplemente, dando cuenta de la ignorancia del ser humano.

Eurípides comprende a sus personajes, sí, pero no les deja el camino franco, y se rebela contra esa realidad que tan bien refleja, clama sobre la terrible dificultad de dilucidar entre actos morales e inmorales, y, al unísono, se niega a proponer una nueva moralidad fundamentada en un poder divino. Lo que sí que formula es una moral que tiene como base la conciencia humana: Orestes y Medea son conscientes de que han obrado mal y que sus actos son una falta contra la justicia y la ley común de los griegos; por el contrario, Ifigenia, al sacrificarse por el bien común, sabe que ha obrado bien.

De esta manera, Eurípides sitúa la adhesión íntima, la conciencia personal como sujeto primario de todo juicio moral. Lo cual rompe con muchos de los valores tradicionales del mundo griego. Por ejemplo, la tesis tradicional por la cual es más importante para ser feliz, el honor, la fama y el poder aún cometiendo una injusticia. Esta valoración de lo interno choca claramente con una tradición que sólo llegaba a valorar lo externo.

La percepción de esta conciencia plantea un nuevo problema, la separación entre acción y pensamiento. Por un lado, en los personajes de Eurípides hay dificultad para hacer lo que piensan, pero no siempre el pensamiento propone bondades, y pensar algo injusto ya sería malo aunque no fuese acompañado de acción. Es el caso de Fedra, cuando declara que sus manos están puras pero su 
alma (otra vez del valor de lo interno) es la que tiene una mancha, el amor por su hijastro Hipólito. Volvemos de nuevo a la importancia del remordimiento, de la mala conciencia interna como la base de todo juicio referido al comportamiento.

Podríamos decir que Eurípides, al igual que los sofistas de su generación, nos deja en un callejón con pocas salidas, incluso en un cierto inmoralismo: ¿por qué Medea tiene que reconocer que ha obrado mal, si le sale bien su plan marcado? Pues sí, lo hace.

Por tanto, Eurípides no sólo muestra sino también pide reflexionar. Puede parecer que en sus obras no observemos ni un enjuiciamiento de las conductas de sus personajes ni de orden religioso (Esquilo, Sófocles), ni social, como propondría la primera sofística. Pero sí hay un enjuiciamiento, el que parte del interior de sus héroes, ya que en algún momento llegan a sentirse responsables de sus acciones. Efectivamente no hay en su obra ni relativismo ni vuelta a la ley del más fuerte.

Ni siquiera está tan cerrado a ese subjetivismo que siempre se le ha atribuido, porque deja intuir lo que está bien y lo que está mal. A veces, incluso, habla del buen gobierno y del aprecio por la figura sencilla, no maleada por los vicios e hipocresías de los demagogos ciudadanos, la figura de esos campesinos que obran rectamente (como el designado esposo de Electra en la tragedia del mismo nombre) y hablan sin rodeos ni malicias. De ahí la predilección de Eurípides de una vida retirada y modesta que anticipa el lema epicúreo de «vive ocultamente», algo dicho, nada menos que por el gran Rey Agamenón, al no poder ni querer resolver el teme del sacrificio de su hija Ifigenia (en Áulide).

Volviendo al eje de la cuestión ética, ahora, con esta nueva moral, al situar como base la conciencia, se tenderá a señalar a cada uno, individualmente, como responsable principal de sus acciones.

Y si aparecen estas cuestiones (conciencia interior y responsabilidad), no significa que vayan unidas a reflexiones profundas, únicamente abren el debate.

Con esto ha venido a concentrarse, a condensarse la inmensa realidad humana, riquísimo, multiforme, que es el teatro de Eurípides. Un teatro que nos hace aflorar a la superficie al «hombre interior» que estaba sepultado por tantas cosas y dioses. Eurípides, en su encuentro con este hombre interior, nos sumerge en lo problemático de la existencia, y, por eso mismo, sienta la necesidad de construir certezas. Ésta será la gran labor de Sócrates y de Platón. Una labor hacia la que Eurípides parece estar pidiendo ir de alguna manera en su descripción de los personajes y de las relaciones humanas.

Con un final si no feliz, sí justo, termina Las Euménides, la tercera obra de la trilogía La Orestiada, de Esquilo. Aunque también en ese final hay algo de felicidad, en sentido literario, y de calma, porque Atenea, mediante el uso debido 
de la razón, ha salvado a Orestes de la condena a muerte por el asesinato de su madre (Clitemnestra), quien a su vez había dado muerte a su padre (Agamenón). Atenea interviene en el proceso, primero, constituyendo un Tribunal formado por los hombres más justos de la Ciudad («irreprochables en la estimación de la ciudad», en palabras de la diosa); luego, obligando a que las partes aleguen argumentos, y finalmente, a la vista del empate técnico de los jueces entre los que consideran culpable a Orestes y quienes no, uniendo el voto al de estos últimos. La cuestión es romper de raíz la serie de venganzas que han acontecido en la familia de los Átridas, para exponer claramente que el crimen no puede contestarse con el crimen, y que es la justicia de la ciudad la que ha de asumir la resolución de los problemas, buscando siempre corregir las causas.

Para ello, Atenea establece un «tribunal insobornable, augusto, protector del país y siempre en vela por los que duermen». Sin embargo, para establecerlo, debe de convencer al coro de las Erinis, las diosas vengadoras de los delitos familiares que provienen de un mundo ancestral y que se habían convertido en fiscales de Orestes, después de perseguirlo. «iHabéis pisoteado la antigua ley...!», le reprochan las Erinis a Atenea, pero ésta les persuade, con buenas razones, recordándoles que sin díke (justicia) no es posible la existencia humana. A partir de entonces, las Erinis se convierten en las Euménides, esto es, en diosas protectoras de la ciudad.

Eurípides añadirá un gran dilema a este final, ya que en su obra Ifigenia entre los tauros, señalará que las Erinis no persiguen a Orestes, sino que están dentro de él. Así, el problema adquiere otra perspectiva, ya que plantea que es la persona, su conciencia interior, la que debe de estar convencida de que algo le obliga moralmente y no sólo por la -digamos-imposición racional de una diosa. Algo parecido señala Habermas en uno de sus últimos trabajos, cuando recuerda su insistente preocupación por la «esfera pública» y la percepción de que en modo alguno «estaba resuelto que los principios de un orden democrático impuesto de cierta manera desde fuera hubiesen arraigado en las cabezas y los corazones de los ciudadanos» (Habermas 2006, p. 28).

Eurípides ya nos estaba conminando a pensar que, como seres humanos, podemos deliberar, elegir, elaborar un plan y jerarquizar nuestras metas, pero también somos seres confusos, incontrolados, pasionales. A fin de cuentas, la razón tiene muchas dificultades para ejercer su control sobre la acción y orientarla hacia el bien común.

Eurípides, ciertamente, sigue definiendo la ley, como antídoto al instinto bestial y sanguinario que destruye de continuo el país y las ciudades, sin embargo, demanda que sea el hombre quien interiorice dicha ley y no provenga de una diosa por muy racional que ésta sea. De lo contrario ese tribunal no será eterno, como quería Atenea, ya que, para su pervivencia, para su permanencia, 
requiere unas condiciones no sólo racionales. Eurípides planteará, por tanto, un problema latente que no termina de perfilar Esquilo: es la persona, su conciencia interior, la que debe de estar convencida de que algo le obligue moralmente. Vemos, pues, una relación entre las «pasiones» (no racionales) y las leyes que instituyen la ciudad (fruto de la razón), lo que nos lleva a pensar que en el origen de las instituciones políticas y de los códigos se encuentran las pulsiones, las aspiraciones..., en definitiva, todo un juego de conflictos.

Eurípides, pues, estaría ya pidiendo el paso de una moral pensada a una moral vivida.

\section{REFERENCIAS BIBLIOGRÁFICAS}

CAMUS, A. 1996: El hombre rebelde, en Obras III. Madrid: Alianza Editorial. DELCOURT, M. 1962: Euripide, Théâtre complet. París: Gallimard.

DI BENEDETTO, V. 1971: Euripide: teatro e società. Torino: Einaudi.

DILTHEY, W.1974: Teoría de las concepciones del mundo. Madrid: Revista de Occidente.

ESQUILO. 2006: Tragedias. Introducción: Francisco Rodríguez Adrados. Madrid: Gredos.

EURÍPIDES. 1990: Tragedias. Madrid: Edaf. 2002. Tragedias. Madrid: Gredos. 2006. Tragedias. Madrid: Gredos.

GARCÍA GUAL, C. 1990: Introducción a Tragedias de Eurípides. Madrid: Edaf. HABERMAS, J. 2006: Entre naturalismo y religión. Barcelona: Paidós Básica. JAEGER, W. 2004: Paideía. Santafé de Bogotá: Fondo de Cultura Económica.

JULIÁ V. E. 2006: «Eurípides: crisis y vuelta a los orígenes. Las Bacantes», en Juliá, V. (ed.) La tragedia griega. Buenos Aires: Azul editorial.

KITTO, H.D.F. 1966: Greek Tragedy, London, A Literary Study.

NIETZSCHE, F. 2005: El nacimiento de la tragedia. Madrid: Alianza Editorial. REINHARDT, K.1972 : Eschyle, Euripide. París: Éditions de Minuit.

RODRÍGUEZ ADRADOS, F.1998: La democracia ateniense. Madrid: Alianza. 1999: Mito clásico y pensamiento contemporáneo. Madrid: Alianza.

SÓFOCLES. 2006: Tragedias, Introducción J. Bergua Cavero. Madrid: Gredos. TUCÍDIDES. 2006: Historia de la guerra del Peloponeso. Madrid: Gredos. 
ENRIQUE HERRERAS es profesor en el Departamento de Filosofía Moral y Política de la Universitat de València. Combina la actividad docente e investigadora con el periodismo, como columnista y crítico de artes escénicas en distintos medios de comunicación.

Publicaciones recientes:

(1996) Una lectura naturalista del teatro del absurdo (Valencia: Universitat de València) (2010) La tragedia griega y los mitos democráticos (Madrid: Biblioteca Nueva)

Línea de investigación:

Dilemas morales planteados en la tragedia ateniense

Dirección electrónica: enrique.herreras@uv.es 
